R. Histórla, São Paulo, p. 127-128, p. 163-179, ago-dez/92 a jan.-jul/93.

\title{
HIGIENE E SEGURANÇA DO TRABALHO EM SÃO PAULO NA PRIMEIRAS DÉCADAS REPUBLICANAS: EM TORNO DA DEFINIÇÃO DE ACIDENTE DO TRABALHO *
}

Esmeralda Blanco Bolsonaro de Moura **

RESUMO: Conferindo destaque ao campo conceitual, atraves da análise dos conceitos de acidente de trabalho e de doença profissional, este artigo tem como finalidade ampliar as perspectivas de conbecimento no âmbito da história do trabalho no Brasil. A abordagem do tema limita-se, cronologicamente, à chamada República Velha, perfodo no qual o Estado esboça suas primeiras tentativas de intervenģăo nas questỏes trabalhistas. A pesquisa tem como referencial, no processo de elaboraçáo da legislaçáo social-trabal hista, o discurso de medicos e juristas e a Lei Federal n 3724, datada de 15 de janeiro de 1919, através da qual o acidente do trabalho e, por extensăo, a doença profissional, sto finalmente objeto de regulamentaçáo especifica.

PALAVRAS-CHAVE: acidente do trabalho, doença profissional, legislaçăo trabalhista, satide, Sto Paulo.

\section{A LEI DE ACIDENTES DO TRABALHO: CONSIDERAÇÕES PRELIMINARES.}

Do interior das fábricas e oficinas para as páginas da imprensa, das publicaçōes oficiais, da literatura médica e juŕ́dica, mobilizando trabalhadores e empresários, médicos e juristas, acirrando as discussōes no Congresso Federal, o acidente do trabalho imprime sua marca na condição operária e na história da legislação social-trabalhista brasileira.

Revelando novos contornos na postura do Estado frente à questão social, a Lei de Acidentes do Trabalho permite, no encaminhamento imprimido à emergencia da regulamentação do trabalho em nível federal, avaliar sobretudo o papel desempenhado pela representação paulista. A atuação do

\footnotetext{
- Versăo modificada do Capitulo I da Tese de Doutorado "O Acidente do Trabalho em Săo Paulo (1890 / 1919)", apresentada ao Departamento de História da FFLCH/USP em 1984.

* Profa. Dra. Departamento de História FFLCH/USP.
} 
MOURA, Esmeralda Blanco Bolsonaro de. Higiene e segurança do trabalho em Săo Paulo aa primeiras decadas tepublicanas: em torno da definiçắo de acidente do trabalbo.

Departamento Estadual do Trabalho, em cujo interior a Lei Federal $\mathbf{n}^{2}$ 3.724/1919 encontraria um primeiro esboço e cuja criação já é sintoma da tendencia ao intervencionismo estatal na questão do trabalho, reflete clara. mente a postura pragmática do Estado de São Paulo frente à acentuada incidencia de greves, frente as proporçōes que assumem movimentos como, por exemplo, a greve paulista de 1917 , postura que passa a apontar então, no sentido da necessidade de regulamentar 0 trabalho. "A aceitação do intervencionismo do Estadon anota Angela Maria de Castro Gomes referindo-se às discussóes travadas na Cámara Federal no perfodo de 1917 a 1919, "através da elaboração de uma legislação social, e o papel desta legislação como instrumento de refreamento do movimento operário são dimensōes da participação dos deputados por S. Paulo nos debates" ${ }^{1}$. Nesse sentido, se a Lei de Acidentes do Trabalho reflete claramente a influência da representação do Estado de São Paulo no cenário nacional, o peso polftico do Estado que, ainda nas palavras de Angela Maria de Castro Gomes, vem "a sofrer mais intensamente os efeitos da questão social" ${ }^{2}$ reflete, igualmente, assim como o conjunto da legislação social-trabalhista brasileira, o nível de atuação da classe operária.

Importante considerar no entanto que, se por um lado a legislação acolbe reivindicaçōes, por outro tende a acomodar o operariado e o movimento operário no conteúdo de suas disposições, diminuindo seu espaço de atuação, sendo, em vários sentidos, disciplinadora de suas ações. É assim que derrogando "formalmente o princípio geral da culpa ${ }^{3}$ a Lei Federal $n^{2} 3.724$ estabelece a obrigatoriedade de indenizar o operário acidentado no trabalho, instituindo no Brasil, em 1919, a doutrina do risco profissional. Aplicado na Europa desde as décadas finais do século passado, bem como no Japăo e em países americanos a partir de princlpios deste século, o risco profissional vem reverter, portanto, uma situação na qual "o operário no Brasil só tinha đireito à indenização quando lograva provar a culpa do patrãon", substituindo a noçăo tradicional de responsabilidade.

1 GOMES, Angzela Maria de Castro - Burguesia e Trabalho: Polfitica e Legislaçäo Social no Brasil, 1917-1937. Rio de Janeira, Campus, 1979, p. 82

2 Idem, p 81.

3 "Legislaço do Trabalho". Boletim do Departamento Estadual do Trabalho, Ano VI, 87 24, 30 trimestre de 1917, p. 411.

4 CASTRO, Arajo-Acidentes do Trabalho. 4 ediçá, revista e aumentada. Rio de Janeiro, Frejcas Bastos, 1935, p.25. 
R. História, Såo Paulo, n. 127-128, p. 163-179, ago-dez/92 a jan.-jul/93.

A Lei de Acidentes do Trabalho - espelhada na legislação social-trabalhista internacional - emerge, no entanto, do moroso processo legislativo, sobretudo como resposta ao Centro Industrial do Brasil: sob o risco profissional, já năo há, formalmente, patrōes negligentes; a avaliação do fenómeno de trabalho objeto de regulamentação já não compete ao operário; a preocupação com "neutralidade técnica", com "objetividade científica" - como bem observa Munakata ${ }^{5}$ - por outras palavras, com precisão, exatidão, resulta numa lei restritiva - inclusive no que, concerne ao "quantum" da indenização que preve -, lei enumeradora que, em última instancia, operacionaliza o fenomeno de trabalho que busca regulamentar. Essa patente operacionalização, está contida já de início, no ato de definir o objeto de regulamentaçăo, assim como nas definições de operário e de patrăo, igualmente contidas na lei e respectivo regulamento. Nítidos mecanismos de defesa no interior mesmo da medida que, ao acolher a doutrina do risco profissional, estabelece a legislaçăo transacional dos acidentes do trabalho.

\section{O CAMPO CONCEITUAL NA LEI FEDERAL NQ 3724/1919: EM TORNO DA DEFINIÇĀO DE ACIDENTE DO TRABALHO.}

"Faltava pouco para terminar o serviço diario na fábrica de fósforas da rua Borges de Figueiredo, 122. Cada operario em seu lugar, as maquinas todas a funcionar regularmente, produzindo o rutdo habitual, quando, subitamente, un grito estridente ecoou pelo estabelecimento. Logo a seguir, o baque de um corpo ao solo. Todos os operários deixaram os trabalhas a que estavam entregues $e$ voltaram-se para o lugar de onde partira o grito: no chäo, banhado em sangue, estava o seu companheiro José Notari, que havia sido colhido pela polia da maquina em que trabalhava.

(...).

José Notari, que é ainda bem moço, pois conta apenas 16 anos, perdeu no desastre o seu braço direito, que foi arrancado pela polia"n.

5 MUNAKATA, Kazumi - A Legislaģäo Trabalhista no Brasil. Săo Paula, Brasilienze, 1981, Tudo é Hisuriria, 32), p. 36.

6 "O Estado de S. Paulo", 23 de janeiro de 1919. 
MOURA, Esmeralda Blanco Bolsonaro de. Higiene e segurança do trabalho em Såo Panlo na primeiras décadas republicanas: em torno da definiçấo de acidente do trabalho.

Datada de janeiro de 1919 , a ocorrencia de que é vitima o operário adolescente José Notari é um exemplo claro de acidente do trabalho e tem lugar alguns dias depois de aprovada, no Congresso Federal, a lei destinada a regulamentar especificamente a matéria. A notf́cia e o excessivo realismo que a ela imprime o jornal, inusitado em se tratando do "O Estado de S. Paulo", não são relevantes apenas por sua simultaneidade com a Lei Federal $n^{\circ} 3.724$, de 15 de janeiro de 1919 , mas porque se inserem no exato momento em que a legislação define formalmente o acidente do trabalho, uma definição que $e$, então, extensiva à doença profissional. $O$ teor da notícia, relevante também em função da exatidão que procura imprimir ao acontecimento, remete para essa definição, já consolidada na alínea $a$ do artigo $1^{2}$ da referida lei, a medida em que a estrutura do texto tende a ressaltar, no acidente que vitima o operário, elementos como subitaneidade e violencia, causa externa e involuntária, lesão corporal que compromete a capacidade para o trabalho. Ressalta, igualmente, o fato de que cada operário estava "em seu lugar" no momento do acidente, isto $\epsilon$, no posto de trabalho e no exercicio da função previstos.

Essa postura nos faz lembrar a pertinente observaçāo de Afranio Peixoto, alguns anos depois, assinalando que' a importancia está nos elementos que caracterizam o definido e não na definição em si mesma ${ }^{7}$, em última instancia, processo seletivo que implica em arrolar e excluir características.

A definição de acidente do trabalho não se esgota, no entanto, no ambito dos elementos que permeiam a notícia acima. Na alínea $a$ do artigo $1^{\circ}$, a Lei Federal $n^{2} 3.724 / 1919$ estabelece que é considerado acidente do trabalho "o produzido por uma causa súbita, violenta, externa e involuntária no exercfcio do trabalho, determinando lesōes corporais ou perturbaçōes funcionais, que constituem a causa única da morte ou perda total, ou parcial, permanente ou temporária, da capacidade para o trabalho", definição que se complementa no artigo $2^{\circ}$ : "O acidente, nas condições do artigo anterior, quando ocorrido pelo fato do trabalho ou durante este, obriga o patrão a pagar uma indenizaçáo ao operário ou a sua família, excetuados apenas os casos de força maior ou dolo da própria vítima ou de estranhos." $O$ alcance da expressăo "força maior" é explicitado no artigo $2^{2}$, parágrafo único do Decreto Federal $\mathrm{n}^{\mathrm{2}} 13.498$ que, em março do mesmo ano, aprova o regulamento contido na referida lei: "Não constitui força maior a açâo das forças naturais,

7 V. PEIXOTO, Afranio, FAVERO, Faminio e RIBEIRO, Leonidio. Medicina Legal das Acidentes do Trabalho e das Doenças Profissionaes. Nocbes de Infortunistica: Doutrina, Pericia, Tec. nica, Legislaģáa. Río de Janeiro, Francisco Alves, 1926. 
R. Htstórla, Såo Paulo, n. 127-128, p. 163-179, ago-dez/92 a jan.-jul/93.

quando ocasionada ou agravada pela instalação do estabelecimento, pela natureza do serviço ou pelas circunstancias que efetivamente 0 cercarem. ${ }^{8}$ Ainda no artigo $1^{\circ}$, alínea $b$, a Lei de Acidentes do Trabalho amplia significamente a definição do fenômeno de trabalho em questão. Sem incorrer na descaracterização de ambos os fenômenos de trabalho, a lei integra a doença profissional ao acidente do trabalho. Primeira medida a regulamentar especificamente a matéria, determina, entáo, no citado dispositivo que seja igualmente considerada como acidente do trabalho "a moléstia contraída exclusivamente pelo exercício do trabalho, quando este for de natureza a só por si causá-la, e desde que determine a morte do operário, ou perda total, ou parcial, permanente ou temporária, da capacidade para o trabalho" 9 . A medida é acompanhada, no citado Decreto Federal $n^{2} 13.498$, de dispositivo parágrafo único, acrescentado ao supra-referido artigo - que visando estabelecer um rol de enfermidades causadas pelo trabalho, considera como "moléstias profissionais, entre outras, (...) o envenenamento pelo chumbo, mercúrio, cobre, fósforo, arsênico e seus derivados, a pneumoconiose, a tabacose pulmonar, a oftalmia amoniacal, o sulfocarbonismo e o hidrocarburismon"10.

A assimilação jurídica do acidente do trabalho e da doença profissional, assimilação que resulta no infortunio do trabalho, "objeto complexo da infortunística" nas palavras de Afrânio Peixoto ${ }^{11}$, institucionaliza a tendencia a interpretar Segurança e Higiene do Trabalho como questões correlatas no ambito das discussões sobre a saúde do trabalhador, tendência essa já observada em fins do século passado. Cumpre lembrar que a Lei de Acidentes do Trabalho deve ser considerada à luz de um contexto no qual saúde e saneamento, higiene e higienização, projetam-se do léxico para a sociedade e para o legislativo particularmente, no interior de um projeto de normatização cuja ótica sobre o espaço urbano "privilegia" como objeto de observação, análise e intervenção, a classe operária e seu cotidiano quer nas fábricas e oficinas, quer fora delas.

Nesse sentido, o fator Segurança do Trabalho em fins do século XIX e princípios deste século é objeto de observação e discussão predominantemente à luz do fator Higiene. Inserido no âmbito da citada preocupaçáo com

8 Departamento Estadual do Trabalho. "Acidentes no Trabalha Lei e Regulamento". Avulso $\mathbf{n}^{\circ} 9$. Sao Paulo, Typ. Levi, 1919, grifo nasso.

9 Idem.

10 Idem, grifo nosso.

11 V. PEIXOTO, Afranio, FAVERO, Flaminio e RIBEIRO, Leonidio op.cit., p.52. 
MOURA, Esmeralda Blanco Bolsonaro de. Higiene e segurança do trabalho em Sáo Paulo aa primeiras decadas republicanas: em tomo da definiçăo de acidente do trabajho.

a higienização do espaço urbano, reforço dessa preocupação no ambiente confinado e frequentemente improvisado das fábricas e oficinas, o enfoque sobre a Higiene se sobrepōe, nesse momento, à preocupaçáo mais espectfica com a Segurança no local de trabalho. Tendo como objeto o controle da insalubridade, que de acordo com a Medicina Legal altera a normalidade organica do trabalhador, afetando sua saúde em maior ou menor grau e evoluindo em muitos casos para a doença profissional, a Higiene prevalece sobre a prevenção do acidente do trabalho e, portanto, sobre o controle da periculosidade, dos riscos aos quais o trabalhador está exposto no exercício de sua função, objeto especifico da Segurança do Trabalho. A questão de fundo contida no interior dessa postura talvez se esclareça na colocação de Afranio Peixoto de que as doenças profissionais ao se transformarem em objeto de reparação revelaram-se "mais evitáveis" do que os acidentes do trabalbo, porque "menos dispendiosas" sendo, portanto, "menos temerosas". "Não tardará muito com o progresso científico - preve o então professor de Medicina Pública da Faculdade de Direito do Rio de Janeiro -, que vai saneando indústrias deletérias, com o saneamento da oficina que vai evitando as ocasiōes de intoxicação e infecção, que a doença profissional desapareça. Será ela quem deixará, agora so, 0 acidente." ${ }^{12}$.

A legislação vigente até a aprovação da Lei Federal n² 3.724/1919 que, em nível quer estadual, quer federal, procura regulamentar a matéria, tende, portanto, a nâo aprofundar o equacionamento nela meramente sugerido, Higiene/Segurança do Trabalho. Os dispositivos que integram os Códigos e Regulamentos Sanitários do Estado de São Paulo, através dos quais são regulamentados alguns aspectos afeitos à relaçōes de trabalho no setor secundário, simplesmente reconhecem a possibilidade de vir o operário a ferir-se no exerćcio de sua profissāo e evidenciam a preocupaçāo mais acentuada dos legisladores com a Higiene, à medida em que nela praticamente centralizam o objeto e o esforço de regulamentaçāo ${ }^{13}$. Não há, na legislação estadual então em vigor, a preocupação de regulamentar especificamente o acidente do trabalho vagamente concebido, nesse caso, como 0 ato do operário machucar-se no desempenho de sua função.

Em nível federal, é no Decreto $n^{2} 1.313$ de 7 de janeiro de 1891 , que o fator Segurança do Trabalho é objeto de preocupação mais incisiva mas, unicamente, em relação aos trabalhadores menores empregados "nas fábricas da Capital Federal", aos quais são proibidas determinadas atividades consi-

12

13 V. Coleçáo das Leis e Decretos do Estado de S5o Paulo, 1889/1920. Sto Paulo. 
R. Histórla, Såo Paulo, n. 127-128, p. 163-179, ago-dez/92 a jan.-jul/93.

deradas perigosas ou prejudiciais. O termo acidente do trabalho, no entanto, não aparece no referido texto legal, estando implicitamente contido na expressão "risco de vida", à qual o legislador recorre no artigo 10, procurando preservar o trabalhador menor do perigo que envolve o desempenho de certas funções $^{14}$.

Em princípios da década de 1910 , a estatística de acidentes do trabaIho, que o Departamento Estadual do Trabalho passa a organizar e a divulgar, vem tornar mais incisiva a preocupação com o fator Segurança sem, contudo, romper com a recorrente preocupaçâo com a Higiene, indicando já a tendencia que se formalizaria em janeiro de 1919 com a Lei Federal $n^{2} 3.724$, a equiparar a doença profissional ao acidente do trabalho.

No ano de 1914, avaliando a incidéncia de acidentes do trabalho, o citado Departamento observa: "As precauções tendentes a evitar os danos que o operário pode sofrer em serviço têm-se restringido, (...) demasiadamente, ao campo da Higiene. Ainda não consideramos como deve ser considerada a ausência de medidas de segurança. ${ }^{15}$.

Nesse sentido, a Lei $n^{\circ} 3.724 / 1919$ e respectivo regulamento vem acomodar no disposto do artigo $1^{\circ}$, que define 0 acidente, aspectos pertinentes à Higiene no Trabalho. Importante acentuar, em relação aos projetos de lei apresentados ao Senado no perfodo e que têm como finalidade regulamentar a matéria, o fato de apresentarem, em termos de definiçăo do acidente do trabalho, posturas diversas. O projeto Medeiros e Albuquerque, datado de 1904, estabelece simplesmente que acidente do trabalho é aquele causado "pelo trabalho ou pelas condiçōes em que ele tem lugar, ou ainda pelos meios de exploração usados." ${ }^{16}$. Em 1908, o projeto Graccho Cardoso considera acidente em seu artigo $3^{\circ}$, "tão somente a ação súbita de uma causa exterior repentina e violenta afetando o organismo externo ou interno do operário, bastante para produzir uma incapacidade imediata que estorve ou embarace - livre exercício de sua atividade", excluindo, "em princípio, todas e quaisquer moléstias profissionais provenientes da própria natureza do trabalho ou contraídas durante o seu curso normal ${ }^{m 17}$. Em 1915, é apresentado ao Senado

14 Decretos do Governo Provisorio da Repáblica dos Estados Unidos do Brasil. Rio de Janeiro, Imprensa Nacional, 1891.

15 "Acidentes no Trabalbo. O Problema Considerado no Brasil". Boletim do Departamento Esta dual do Trabalho, Ano 1II, $n^{2} 11,2^{\circ}$ trimestre de 1914, p. 284.

16 "Os Tres Projetos de Lei Relativas a Acidentes no Trabalho". Baletim do Departamento Estadual do Trubalho, Ano V, $\mathrm{n}^{\circ} 21,4^{\circ}$ trimestre de 1916, p. 572.

17 Idem, p 579. 
MOURA, Esmeralda Blanco Bolsonaro de. Higiene e segurança do trabalho em Såo Paulo na primeiras decadas republicanas: em torno da definiçåo de acidente do trabalbo.

- projeto Adolpho Gordo que, elaborado pelo Departamento Estadual do Trabalho acolhe a doutrina do risco profissional. A Lei de Acidentes do Trabalho seria aprovada em 1919, na vigencia da Comissão Especial de Legislaçăo Social que, criada na Camara Federal em 1918, com a função de reestudar todas as leis propostas, teria a seu encargo a elaboração da legislaçăo social-trabalhista.

A definição de acidente do trabalho encontraria no esboço de projeto de lei sobre os acidentes do trabalho, organizado no ano de 1914 pelo Departamento Estadual do Trabalho, depois projeto Adolpho Gordo, a elaboração formal definitiva. Considerando, entāo, "ilogica" e "injusta" a exclusão da doença profissional "do número dos fatos que dão lugar à aplicação da Lei", o Departamento em questão afirma sua convicção de que "Em boa justiça, ao operário atingido, muitas vezes mortalmente, por uma moléstia profissional, devia conferir-se o mesmo direito que tem a uma reparação o operário vitima de um acidente ${ }^{18}$. Assim, o parágrafo $1^{2}$ do artigo $1^{\circ}$ do referido esboço de projeto de lei:

"Os acidentes a que se refere esta Lei são os produzidos por uma causa exterior súbita ou violenta, que lesam o corpo humano ou lhe determinam a morte.

Também darão lugar à aplicação da Lei os danos que os operários sofrerem na exploração das indústrias que, por sua natureza, puderem ocasionar enfermidades agudas ou intoxicações cronicas" ${ }^{19}$.

É assim que ao proceder mensalmente à estatistica de acidentes, o Departamento inclui todos os eventos súbitos que consegue apurar no trabalho. Isso, não só nos setores secundário e terciário - onde inclui também os operários do Estado e do Munić́pio - mas, numa atitude verdadeiramente pioneira, também na esfera privada dos serviços domésticos, mais especificamente, da dona-de-casa que se fere em uma de suas tarefas quotidianas. No caso específico do setor secundário, o acidente é considerado em sua relação com o trabalho propriamente dito, sendo arroladas como tal as ocorrencias que vitimam o trabalhador no local de trabalho, em transito para o serviço ou a serviço da empresa. Dessa forma, são considerados como acidentados do trabalho, operários que tem vertigens, ataques histéricos, síncopes, situações que, embora súbitas, estariam, por princípio, mais diretamente relacionadas

18 "Eubogo de Projeto de Lei sobre es Acidentes no Trabal to". Boletim do Departamento Estadual do Trabal ho. Ano III, if 11, $2^{\circ}$ trimestre de 1914, p. 353.

Idem, p. 325. 
R. Histórla, Såo Paulo, n. 127-128, p. 163-179, ago-dez/92 a jan.-jul/93.

à saúde e não à segurança do trabalhador. O Departamento Estadual do Trabalho, no entanto, näo considera a doença profissional como um acidente do trabalho. Prevê, apenas, uma equiparação entre os dois fenômenos procurando preservar a especificidade de cada um na situação de trabalho. É somente no texto da Lei Federal $n^{2} 3724 / 1919$ que o acidente do trabalho absorve a doença profissional. Essa absorção formal não implicaria, no entanto, em nova conceituação dos fenómenos frente à realidade de trabalho. A partir de uma perspectiva que considera a doença profissional e o acidente do trabalho como igualmente danosos à capacidade de trabalho do ser humano, ainda que atuando de forma diversa sobre ela, a legislação federal, como o fazem as legislações alemã, espanhola, suiça, italiana, inglesa, grega, mexicana, argentina, japonesa, bem como a legislação dos Estados Unidos em geral, considera ambos os fenômenos como indenizáveis. Doença profissional e acidente do trabalho são, assim, equiparados na natureza, distintos na causalidade e nas circunstancias em que ocorrem e se manifestam, equiparando-se novamente no objeto específico da legislação, a reparação dos danos causados à capacidade de trabalho do ser humano no exercício da profissão.

A assimilação jurídica da doença profissional ao acidente do trabalho, que confere nova dimensão à Medicina Legal através da Infortunística, mobiliza a literatura médica e jurfdica, assim como a operacionalizaçăo contida na proposta de definir os fenómenos de trabalho que regulamenta traz à tona claras manifestações de discordancia. É nesse contexto que Afranio Peixoto, Flaminio Favero e Leonidio Ribeiro, através de obra especifica, introduzem formalmente a Infortunística na literatura juridica brasileira, conferindo espaço privilegiado ao acidente do trabatho e à doença profissional no campo da Medicina Legal. A proposta de "fazer livro prático e didático, que sirva de auxílio a estudantes de medicina e de direito, a peritos e magistrados ${ }^{n 20}$ que se viabiliza em larga medida na análise da legislação em vigor, à luz da legislação social-trabalhista internacional, que lhe serve de modelo, resulta numa verdadeira fragilização da Lei Federal $n^{2}$ 3.724/1919. Uma fragilização que se concretiza, em larga medida, no campo conceitual. Para Afranio Peixoto, a definição de acidente do trabalho contida na legislação brasileira "peca logo de começo por não abranger senão parte do definido", uma vez que os termos da alínea $a$ não abrangem "a parte considerada também acidente na alínea $b .{ }^{21}$.

Os termos como é formulada a definição de acidente do trabalho na Lei Federal n².724/1919, extensiva à doença profissional, sem deixar, no entan-

20 V. PEIXOTO, Afranio, FAVERO, Flaminio e RIBEIRO, Leonidia op.cit., p 10.

21 Idem, p28. 
MOURA, Esmeralda Blanco Bolsonaro de. Higiene e segurança do trabalho em Săo Pado na primeiras decadas republicanas: em tomo da definiçáo de acidente do trabalbo.

to, de defini-la diversamente, conduzem, de fato, à necessidade de tornar precisa a conceituação de acidente-tipo ou típico - isto $E$, acidente do trabalho propriamente dito -, por oposiçāo à doença profissional. Em 1926, Mariano Leonel Netto em tese apresentada à Faculdade de Medicina de São Paulo conclui que "o termo acidente deve ficar reservado para o dano agudo". Propōe, então, em clara alusāo à Infortunística, o uso da expressão "infortúnios do trabalhon que, menos específica e mais abrangente, tornaria possivel falar simultaneamente em acidente do trabalho - "dano agudo" - e em doença profissional - "dano crónico" - sem o risco de equívocos e sem incorrer na possivel descaracterização dos fenomenos de trabalho em questão22.

Em meados da década de 1930, Araújo Castro, embora considerando que "a distinção entre acidente do trabalho e moléstia profissional não tem grande importancia", uma vez que a "nossa legislação (...) equipara esta àquele para todos os efeitos" procura, a partir da literatura jurídica quer nacional, quer internacional, caracterizar o acidente-tipo - aquele em que há a presença de violência pequena ou grande - e definir a doença profissional, "aquela que é diretamente determinada pela profissão", invadindo "pouco a pouco o organismo, sem que seja possível indicar precisamente seu início". No ambito do debate jurídico, esclarece, a doença profissional surge como "consequencia do exercício habitual de certa indústria", caracterizando-se "por uma causa contínua e durável" - afastada, portanto, a possibilidade de determinar o início preciso de sua manifestação -, enquanto o acidente do trabalho é considerado como "resultado de um fato súbito e claramente determinado". Assim, anota, enquanto o acidente "é um acontecimento imprevisto" - elemento que, conforme veremos, é contestado por Afranio Peixoto -, a doença profissional "constitui um risco quase certo do exercício da profissão", distinção extensiva à circunstancia de ter esta última, sua causa num acidente do trabalho. Caracterizada então, como "resultado de causas inerentes ao exercício normal e habitual da profissão", a doença profissional se define por "oposição formal ao acidente, fato anormal". Ressalta, ainda, que sendo o acidente do trabalho um fenomeno sempre evidente, o seu nexo com o trabalho é fácil e imediatamente estabelecido, enquanto a doença profissional, à medida em que frequentemente constitui uma lesão organica nāo evidente, nem sempre permite perceber o seu relacionamento com as

22 LEONEL NETTO, Mariano. "Do Estado Anterior nos Infortunios do Trabalho (Contribuiçăo ao seu Estudo).". Tese apresentada em dezembro de 1926 a Faculdade de Medicina de S. Paulo (Cadeira de Medicina Legal). Såo Paulo, Irmatos Ferraz, 1926, p.18. 
R. História, Sáo Paulo, o. 127-128, p. 163-179, ago-dez/92 a jan.-jul/93.

conđições de trabalho ou, mais especificamente, com a função desempenhada pelo operário. Em resumo, a doença profissional evoluiria sutil, lenta e progressivamente, enquanto $o$ acidente do trabalho seria resultado de um fato súbito e violento ${ }^{23}$.

De fato, o acidente surge, nos documentos em geral, relacionado a morte ou à perda ou diminuiçăo da capacidade de trabalho do ser humano na relação direta com a produção. Sinônimo frequente de "desastre", é entendido como o momento preciso, bem definido, em que o trabalhador tem sua integridade física violada de forma súbita - portanto inesperada - e violenta, no exercício da profissão. Por oposição, a doença profissional é concebida não só como inerente ou peculiar a determinadas funções mas, considerado o caso específico da tuberculose, também como as que se agravam em virtude das condiçōes de trabatho.

Na própria conceituação do trabalhador, o acidente está normalmente relacionado d violencia e ao traumatismo. Define-se como o momento em que o operário ou perde a vida ou tem, de forma contundente, sua capacidade de trabalho atingida e, frequentemente, diminurda. Assim emergem das "Lembranças do Sr. Amadeu", os acidentes do trabalho testemunhados na oficina de gravura na qual ingressou ainda menino:

"Tínhamos um laminador. Laminador é aquele cilindro de aço onde a gente póe o material de um lado bem grosso e ele sai fino do outro lado. $\mathbf{E}$ uma máquina perigosa. Uma ocasiāo, um senhor foi laminar umas peças $c$ uma correia, uma polia, pegou o braço dele. Quebrou o braço, a mão, abriu a cabeça; enfim, o homem ficou inutilizado. Esse é um dos desastres que lembro, dos que foram mais perigosos. Mas na estamparia cortavam todo mes um dedo, dois dedos, cada operário. ${ }^{24}$.

$O$ industrial Jorge Street, em entrevista concedida ao "Jornal do Comércio" do Rio de Janeiro e publicada no "O Estado de $S$. Paulo" em setembro de 1917 refere-se ao acidente do trabalho relacionando-o igualmente à periculosidade, fazendo menção "aos perigos, em geral, inevitáveis a que estăo sujeitos" os operários na "grande indústria moderna" e que "produzem acidentes, que passam por toda a escala da gravidade, indo às vezes ate a morte $^{\text {25 }}$.

23 CASTRO, Aratjo - op.cit., p.50/64.

24 BOSI, Bclá -Memória e Sociedade: Lembranģas de Velhas. Sso Paula, T. A. Quedrue Bditor, 1983 p. 85.

25 "O Eatado de S. Paulo", 19 de setembro de 1917, p. 9/10. 
MOURA, Esmeralda Blanco Bolsonaro de. Higiene e segurauça do trabalho em Săo Paulo da primeiras decadas republicanas: em torno da definiçấo de acidente do trabalho.

Como se percebe, a importancia que Afranio Peixoto confere aos elementos que caracterizam o definido encontra seguro respaldo na abordagem do acidente do trabalho e da doença profissional no campo conceitual. A definiç̧ăo se esclarece, se amplia ou se esgota, se fortalece ou se fragiliza no ambito de uma terminologia que busca ser precisa ao caracterizar os fenomenos de trabalho objeto de regulamentação. Nesse sentido, expressōes como involuntário, causa externa, subitaneidade, violência, exercício do trabalho, fato do trabalho, durante o trabalho - no caso do acidente -, bem como causa única, no caso da doença profissional acabam sendo, no fundo, elementos adequados a uma interpretação restritiva da lei, que freiam a possibilidade de efetivo avanço social.

Ao definir o acidente do trabalho a lei que regulamenta a matéria procura definir o seu próprio campo de aplicação. Definir é "Explicar o significado(...), indicar o verdadeiro sentido". É "Dar a conhecer de maneira exata; expor com precisão" 26 . Mas, no campo jurídico, alerta Afranio Peixoto, as definiçōes "são meio de limitação." ${ }^{27}$.

Conforme enfatizamos anteriormente é sobretudo no campo conceitual que se concretiza a mais evidente fragilizaçäo da Lei de Acidentes do Trabalho. Fundamentando-se em grande parte na literatura juridica internacional, Afranio Peixoto ve como equivocados os elementos a partir dos quais são construfdas as definições de acidente do trabalho e de doença profissional. Subitaneidade e violencia restringem o alcance da lei, a primeira porque exclui a lesáo resultante de uma "acumulação de efeitos", o acidente do trabalho que não resulta de "causa 'subitanea'" mas, de causa "mais ou menos prolongada", sem deixar de ser típico; a segunda,porque limita o entendimento do fenomeno de trabalho ao acidente mecanico. Igualmente equivocada, a expressáo "causa externa": ao tentar distinguir o acidente-tipo da doença profissional, a legislação não considera a possibilidade desta vir a ser adquirida também através de uma causa externa - como o saturnismo, por exemplo -, assim como exclui a possibilidade de estar, $o$ acidente do trabalho, relacionado a causas internas como é o caso das consequencias do esforço violento para uma hérnia. É onde se coloca, com pertinência, a noção de estado anterior de saúde do operário ao acidente do trabalho ou, juridicamente, concausa preexistente. Em contrapartida, a expressão "exercício do trabalho" - que pode ser interpretada, restritivamente enquanto lugar do trabalho -

26 FERREIRA, Aurelio Buarque de Holanda - Novo Dicionáio da Lingua Portuguesa 24 ediço, revista e ampliach. Rio de Janeiro, Nova Fronteira, 1986, p. 528.

27 V. PEIXOTO, Afranio, FAVERO, Flaminio e RIBEIRO, Leonidia op.cit., p.26. 
R. Historfa, Såo Paulo, n. 127-128, p. 163-179, ago-dez/92 a jan.-jul/93.

pode, igualmente, ser objeto de uma interpretação extensiva ou, nas palavras de Afranio Peixoto, "se o risco profissional é coberto ao operário, e náo ao homem, a investidura do primeiro começa desde o momento em que deixa o seu lar 'para o trabalho', até aquele em que 'do trabalho' se reintegra no seu lar.". Por outro lado, a expressão "involuntária" visa excluir o dolo ou a culpa. A questão que Afranio Peixoto coloca é se, ao dizer que o acidente deve ser involuntário, estaria a lei brasileira querendo dizer que o acidente deve ser imprevisto. "A vontade, a intençāo, esclarece, criaria o dolo, a culpa, que não têm cabimento aqui, e apenas no direito comum, embora por ele passivel de reparação...". E prossegue: "Como conciliar o aciđente, que etimologicamente, lexicamente, é imprevisto, é fortuito, ocorre a caso, com o acidente de trabalho, que é constante, fatal, necessário, dados os perigos inerentes ao trabalho e a psicologia da falibilidade humana, em uma palavra, dado o risco profissional?". O caráter de "imprevisão" do acidente do trabatho é portanto dispensável, conclui, uma vez que tanto o mesmo é "previsto (...), que um direito novo se impos, reparador ao dano que ele causa ${ }^{\mathrm{m} 28}$.

No caso da doença profissional, a legislação se fragiliza no momento em que a define como "moléstia contraída exclusivamente pelo exercício do trabalho", um critério através do qual alerta mais uma vez Afranio Peixoto já "não haverá doenças profissionais", porque restrito em demasia ${ }^{29}$. "Tal etiologia, 'exclusiva', é incomportável - esclarece -; nem a fadiga, a estafa aguda e crônica 'pelo exercício do trabalho', pode ser considerada, 's6 por si', obra dele: o mesmo trabalho cansa a um e deixa indene a outro operário; contam para isto o estado anterior e circunstancias proprias concurrentes com a causalidade principal. É imaginária a noção de causa única, exclusiva de um fenomeno. ${ }^{\text {30 }}$.

Paralelamente, a enumeração das doenças profissionais contida no decreto Federal $n^{2} 13.498$, acompanhada da expressāo "entre outras" - que contém em suma, "tudo o que se puder provar como doença ou risco profissional $^{31}$ - tende a esvaziar o caráter social preventivo que pode estar contido na legislação, à medida em que espelhada na legislação argentina, não contempla a especificidade do meio brasileiro. Nesse sentido, se o parágrafo único acrescentado ao artigo $1^{2}$, alínea $a$, da Lei de Acidentes do Trabalho pelo referido Decreto que lhe dá execução, comporta, por um lado, uma

Idem, p. 26/41.

Idem, p.53.

Idem, p. 105/106.

Idem, p 107. 
MOURA, Esmeralda Blanco Bolsonaro de. Higiene e segurança do trabalho em Săo Paulo na primeiras decadas republicanas: em torno da definigho de acidente do trabalho.

interpretaçăo extensiva da legislação, favorecida pela expressão "entre outras", por outro lado, a enumeração das moléstias profissionais nele contida não deixa de ser restritiva.

A assimilação jurídica dos fenômenos de trabalho em questão, medida justa e de interesse social, não impede que a Lei de Acidentes do Trabalho, ao considerar diferentemente acidente-tipo e doença profissional respectivamente nas alíneas $a \mathrm{e} b$ do artigo $1^{2}$ enverede definitivamente pelo caminho das restriçōes.

Assim, a definição que Afranio Peixoto oferece de acidente do trabalho, definição "que se adapla às duas alíneas do art. $1^{\circ}$ da nossa lei: 6 toda lesão corporal, ou perturbação funcional, ou doença, ou morte, produzida no exercício ou por causa do exercício profissional e que determina limitação ou suspensão permanente ou temporária da capacidade no mesmo trabalho. ${ }^{32}$.

A complexidade das questöes referentes ao trabalho no campo conceitual - impossível de ser plenamente contemplada no ambito de um artigo encontra nos processos de acidentes do trabalho documentação das mais interessantes, à medida em que os mesmos permitem surpreender as disposiçōes previstas na legislação sob a ótica da interpretação jurfdica. Mais uma vez os clementos em torno dos quais é construída a definiçāo de acidente do trabalho ganham força enquanto elementos que conduzem a uma interpretação restritiva da legìslação e se projetam dos autos acima de tudo enquanto recurso que, em larga medida, subvertem a garantia de reparação prevista na lei.

Nos termos da Apelaçāo Cível n 12.128, datada de princípios da década de 1920 , o advogado de J. Ramalho \& Cia., por exemplo, justifica a apelaçăo contra a decisão de pagar a Maria Gatti Cesar indenização pela morte de seu filho, de 17 anos, em estabelecimento do apelante, afirmando não se tratar de um acidente do trabalho. E justifica:

"A vftima foi vítima de sua imprudencia, da sua própria vontade, pois não trabalhava na amassadeira que lhe causou a morte e, como ficou provado dos autos, meteu o braço no interior da mesma, no intuito de fazé-la parar. Ora, não há negar que tal acidente tenha sido voluntário. A vítima o procurou.

Mas, a lei (art. 1, letra a) só cogita dos acidentes involuntários".

Fundamentando suas convicçōes, $O$ advogado esclarece que " $O$ acidente năo teve lugar durante o trabalho da vítima", uma vez que esta trabalhava "junto ao forno, pois era ajudante do forneiro, em compartimento diverso 
R. Historia, Sao Paulo, a. 127-128, p. 163-179, ago-dez/92 a jan.-jol/93.

daquele em que funcionava a amassadeira fatal", sendo que "o desastre" năo teria acontecido se a mesma tivesse permanecido "no seu trabalho". Ao concluir, no caso, pela imprudencia do trabalhador acidentado, o advogado acentua que $o$ acidente foi provocado pela própria vítima ao agir "dolosamente": "a vítima - ressalta - sabia que não devia abandonar o seu posto $e$, escondidamente, transgredindo ordens, deixou o seu trabalho e passou a outro compartimento. A amassadeira é máquina que não oferece perigo algum, senão àqueles que quiserem, como a vitima, criar tal perigo. A amassadeira é máquina que funciona dentro de um grande barril", no qual "movem-se as pás. A vítima, chegando ao compartimento em que essa máquina funcionava sob a direção da 3' testemunha, disse: 'sou capaz de fazer parar essa máquina' e, ajuntando a ação à palavra, meteu o braço para dentro do recipiente em que se movia o maquinismo, a fim de alcançar uma das pás e rete-la. Năo o conseguiu, sofrendo lamentavelmente, as consequencias de sua culpa e do seu dolo. Dolo, por deixar o seu afazer e culpa por procurar propositalmente o acidente ${ }^{33}$.

Da mesma forma, em 1930, em processo que o operário Bruno Kuhn move contra a Companhia Antárctica Paulista, alegando haver perdido a vista esquerda em virtude de trabalhar "frente a uma porta" que "sempre se conservava aberta" , motivo pelo qual "recebia constantemente muito vento, principalmente no rosto", é clara a distinção - nas razóes do agravo do autor entre acidente do trabalho e doença profissional:

"O agravante não alega haja sofrído um 'acidente' no sentido estrito de traumatismo, 'causa súbita, violenta', mas 'moléstia' contraída pelo exercício do trabalho que prestava à agravada".

O laudo pericial é, no entanto, manifestamente contrário ao pedido de indenização apresentado pelo autor:

"Na história relatada (pelo operário) - anota o perito - năo se encontra um ponto sequer que se possa atribuir a um acidente do trabalho a perda do seu olho. Năo houve traumatismo e não temos base para afirmar que o paciente sofreu uma molestia adquirida no trabalho" ${ }^{\text {34 }}$.

No primeiro caso, coloca-se em evidencia o vínculo que a Lei Federal $\mathrm{n}^{2} 3.724 / 1919$ estabelece, no artigo $1^{2}$, alínea $a$, entre acidente e efetivo "exercício do trabalho", reforçado no artigo $2^{\circ}$ na expressäo "acidente(...)

Apeisçáo Civel no 12.128, Capital, 1921. Apelantes: J. Ramalbo \& Cle. (Patrio). Apelados: Maria Garti Cesar (Assistida de seu marido), (mite da vitima).

34 Agto Sumbris de Acidente do Trabalbo, Capital, 1930. Vitima: Bruno Kubn. Patrio: Companhia Antarctica Paulista. 
MOURA, Esmeralda Blanco Bolsonaro de. Higiene e segurança do trabalho em Sx̌o Padlo na primeiras décadas republicanas: em torno da definiçăo de acidente do trabalho.

ocorrido pelo fato do trabalho ou durante este", vínculo que prevalece sobre a "causa súbita, violenta, externa e involuntária" que igualmente define o acidente do trabalho. Além disso, a noção de acidente voluntário faz emergir a açáo dolosa, o "dolo da própria vítima", que prevalece sobre a alegação constante do Auto circunstanciado do acidente, de que o mesmo teria "sido devido à falta de proteção da referida máquina", no caso, uma amassadeira. "Dolo da própria vftima", esclarece Afrânio Peixoto, é uma categoria que implica em acidente intencionalmente provocado, crime, falta inexcusável, infrações disciplinares voluntárias, intemperança, negligéncia ${ }^{35}$ - situaçóes que o princípio do risco profissional não contempla - e que permanece em aberto na Lei Federal $n^{\circ} 3.724 / 1919$, escapando convenientemente da excessiva operacionalização que a caracteriza.

No segundo caso, a ausencia de traumatismo, subitaneidade e violencía afasta a possibilidade de considerar o dano sofrido pelo operário como um acidente do trabalho e faz emergir, na avaliação dos fatos, a questão do estado anterior de saúde do trabalhador, conforme enfatizara Mariano Leonel Netto ao propor, na citada tese apresentada à cadeira de Medicina Legal da Faculdade de Medicina de São Paulo, em meados da década de 1920, a exigencia de exame médico prévio à admissão ao trabalho. O caráter insidioso da doença profissional, a dificuldade de determinar o início de sua manifestação, de estabelecer o nexo causal exclusivo com o trabalho, constituem, assim, sérios obstáculos à indenizaçăo, consequentemente, à aplicação plena da lei.

Paralelamente, evidencia, subitaneidade, violéncia, traumatismo, se estáo presentes, explícita ou implicitamente, na definição de acidente do trabalho náo esgotam sua plena caracterização e, como tal, não constituem, igualmente, garantia de indenizaçāo. Ressalte-se a importância conferida ao "exercicio do trabalho", às noçōes de "fato do trabalho", "durante o trabalho", quer se trate de acidente típico, quer de doença profissional, por mais "relativo e instável" que possa ser "o conceito de causa e efeito, entre o trabalho e o acidente indenizáve ${ }^{\text {+36}}$. Nos termos da notícia do "O Estado de S.Paulo", acima transcrita, confere-se destaque ao fato de que o operário, ao se acidentar, estava "em seu lugar", de que as máquinas estavam "todas a funcionar regularmente, produzindo o rufdo habitual...". 
R. Histórla, Sáo Paulo, n. 127-128, p. 163-179, ago-dez/92 a jan.-jul/93.

Num momento em que grande parte das fábricas e oficinas primam, em suas instalações, por uma evidente improvisação e pela ausência quase absoluta de equipamentos visando a proteção do trabalhador, o fato do operário estar "no exercício do trabalho" emerge da legislação como garantia de indenização e; se considerarmos as convicções do advogado de J. Ramalho \& Cia. na Apelação Cível n 12.128 , parcialmente transcritas acima, numa larga medida, como garantia de segurança.

Considerada mera tentativa de "acalmar os meios operários ${ }^{\text {r37 }}$, a Lei Federal $n^{2} 3.724 / 1919$, lei fundamentalmente de reparação, faz do seu proprio campo de aplicação, a partir da operacionalização excessiva do objeto de regulamentação, caminho seguro para uma interpretação restritiva, um terreno inevitavelmente movediço. Talvez por isso mesmo, tenha imprimido sua marca na história da legislação social-trabalhista brasileira, enquanto projeto que, conseguindo um certo consenso, seria "aprovado, quase sem alteração ${ }^{\text {n38 }}$, quer pela Câmara dos Deputados, quer pelo Senado. Afinal, nas palavras do jornal "Gazeta de Notícias", comentando, alguns anos depois, o projeto de revisão da própria Lei de Acidentes do Trabalho, "O legislador, elaborando o direito obreiro, precisa ter muito cuidado com a Jurisprudencia, que galopa adiante das intençōes do poder legislativo" ${ }^{39}$.

ABSTRACT: Giving greater emphasis to the field of conception, through the analysis of concepts such as labor socidents and professional diseases, this article's objective is to expand the perspectives of knowledge in the sphere of labor history in Brazil. The analysis of the topic limits itself, chronologically, to the so-called Old Republic, a period in which the State outlines its first attempts of intervention in labor issues. The research has as its reference point the speeches of physicians and jurists as well as the Federal Law $n^{0} 3724$, dated January 15, 1919, through which labor accidents apo professional diseases finally are subjects of a specific regulation.

KEY-WORDS: labor accident, professional disease, Labor Legislation, health, Sáo Paulo. 